\title{
Biodosimetry using chromosomal translocations measured by FISH in a population chronically exposed to low dose-rate ${ }^{60} \mathrm{Co} \gamma$-irradiation
}

\author{
W. A. HSIEH $\dagger$, J. N. LUCAS $\ddagger$, J. J. HWANG§, G. C. CHAN
}

(Received 22 December 2000, accepted 22 March 2001)

\begin{abstract}
.
Purpose: To evaluate the cumulative $\gamma$-radiation personal exposure by analysing lymphocyte chromosome translocations using FISH painting and to compare FISH-derived biodoses with those derived from retrospective physical dose reconstruction in residents receiving chronic low dose-rate $\gamma$-irradiation while living in radio-contaminated buildings.

Materials and methods: Chromosome translocation frequencies were evaluated by scoring 933 to 3077 metaphases under fluorescence microscope for each of the five male and four female exposed individuals after they had relocated from the radioactive environment for 34-82 months. FISH painting was conducted using kits of whole-chromosome probes for chromosomes 1, 2 and 4 in orange and 3, 5 and 6 in green and counter-stained with 4',6-diamidino-2-phenylindole (DAPI). The retrospective dose estimation termed Taiwan Cumulative Dose (TCD) was conducted by assessment using detailed information of historical exposure and the environmental radioactivity for each apartment during previous residency.

Results: A total of 20244 well-prepared metaphases were scored. Biodoses were calculated from the translocation frequencies and physical doses were estimated from detail questionnaires for each individual. The translocation frequencies measured ranged from $2.2 \times 10^{-3}$ to $26.8 \times 10^{-3}$ translocations per cell and the dose equivalent from 52.2 to $992.2 \mathrm{mSv}$. A good correlation was observed between the physical and biodoses. A plot of TCD against FISH-derived doses produced $D_{\text {fish }}=0.65 D_{\text {TCD }}$, when fitted by a linear model, and $D_{\text {fish }}=0.53 D_{\mathrm{TCD}}+1.26 \times 10^{-4}$ $D_{\text {TCD }}^{2}$, when fitted with a linear-quadratic model. Given the scatter in the data and the extremely small quadratic dose contribution, neither model could be ruled out.

Conclusion: Chromosome translocations provide a valid method of dose estimation in extremely protracted low dose-rate $\gamma$-radiation exposure. Validation of the TCD method by FISH-measured translocations supports the use of TCD for epidemiological studies.
\end{abstract}

*Author for correspondence at National Yang Ming University; e-mail: wpc94@ym.edu.tw

$\dagger$ Institute of Environmental Health Sciences, School of Medicine, National Yang Ming University, 155, Section 2, Lih-Non Street, Taipei, Taiwan 112.

†Lawrence Livermore National Laboratory, CA, USA.

$\S$ Institute of Radiological Sciences, National Yang Ming University, Taipei, Taiwan.

ๆInstitute of Occupational Medicine and Industrial Hygiene, College of Public Health, National Taiwan University, Taiwan.

| Department of Family Medicine, Taipei Jen-Ai Municipal Hospital, Taipei, Taiwan.

\section{Introduction}

A fast and reliable approach to estimate the dose for individuals chronically exposed to ionizing radiation over a protracted period is essential. In past studies, biological methods of dose estimation methods have been used in cases such as the A-bomb survivors, the nuclear accident at Chernobyl (Salassidis et al. 1995), occupational exposures (Straume et al. 1992), and astronauts travelling in space for several years (Straume and Bender 1997). These studies were mainly conducted on individuals with short-term acute high doses of exposure. The dose reconstruction for individuals with previous long-term and low dose-rate radiation exposure has, however, seldom been reported.

From late 1982 to 1983,20000 tons of ${ }^{60} \mathrm{Co}-$ contaminated steel were produced and accidentally used in civilian construction in Taiwan (Chang and Kau 1993, Chang et al. 1997a). Until the end of 1999, more than 100 building complexes, 1600 apartments, and school classrooms were confirmed to have elevated levels of $\gamma$-radioactivity in the living environments. More than 6000 citizens were identified who had been exposed to protracted low dose-rate $\gamma$ radiation exposure in Taiwan (Chang 1993). Most were exposed to a daily excess low dose-rate $\gamma$ irradiation in their living environments over several months and for up to $>10$ years. Studies on these low dose-exposed cohort populations have provided several interesting observations, including increased frequencies of lens opacities (Wang et al. 1999, Chen et al. 2001), elevated levels of DNA damage such as lymphocyte micronuclei (Chang et al. 1997b), persistent depression in the haematopoietic cells, e.g. decrease in the peripheral neutrophils (Chang et al. 1999a), altered distribution in lymphocyte subpopulations (Chang et al. 1999b), and delay in physical height development in children (Wang et al. 2001).

In order to understand the dose-response in various health outcomes, a physical dose reconstruction programme was initiated in 1994 by a NOISH prototypical model (Cardarelli et al. 1997) and later 
modified by incorporating 'highly occupied zone' approach and termed the 'Taiwan Cumulative Dose' or TCD for the derived dose estimation (Hwang et al. 1998). The TCD model is based on the cumulative exposure duration of the individuals in the specific environment and conditions of exposure, and addresses factors such as geometry and physical layout of indoor rooms, living styles and change in seasonal occupancy patterns, background radioactivity, and ${ }^{60} \mathrm{Co}$ decay in the radioactive environment. Upright sitting or standing positions were assumed during environmental surveillance for the exposure. The TCD estimation was, therefore, designed to represent exposure of the whole body trunk and acted as a surrogate for bone marrow exposure. The average excess dose-rate derived from TCD was estimated to be $\sim 30-40 \mathrm{mSv}$ year $^{-1}$ for most of these individuals. However, because of uncertainty due to imprecise recall of residence history over such extended periods of residency and variation in living locations, the doses estimated by physical dose reconstruction or the TCD model need further validation. An appropriate biodosimetric model for estimating cumulative exposure in these exposed individuals is thus required.

Chromosome translocation frequencies have been used to estimate doses of exposure even decades after whole-body radiation exposure. For example, six rhesus monkeys were exposed to acute single-dose whole-body proton irradiation ranging from 0.56 to $2.25 \mathrm{~Gy}$ in 1965 and were shown to have good agreement between dose estimated by calculating frequencies of reciprocal translocations using human chromosome painting three decades later (Lucas et al. 1996). Estimated dose using FISH analysis after decades were shown to be approximately the same as those estimated by translocation frequencies measured using G-banding for 20 Hiroshima A-bomb survivors exposed in 1945 and four accident victims who worked at the Y-12 plant in Oak Ridge in 1958 (Lucas et al. 1992). In another study the dose received by a radiation worker with 36 years of occupational exposure to ionizing radiation was estimated to be $0.56 \mathrm{~Sv}$, based on his exposure record during that period; using FISH-painted chromosome translocation analysis (Straume et al. 1992), his biodose was estimated to be $0.6 \mathrm{~Sv}$. Chromosome painting has also been employed to evaluate the stability of symmetrical translocations in 12 highly irradiated liquidators of the 1986 Chernobyl accident from blood samples collected from September 1991 to July 1994 (Salassidis et al. 1995). These studies suggest that analysis of translocation frequencies in peripheral lymphocytes is a feasible biodosimeter for historical exposure.
Some studies have, however, suggested that the maintenance of a constant level of stable reciprocal translocations cannot be expected from FISH painting for translocations, particularly on bone marrow involved during fractionated photon radiotherapy or partial-body exposure (Huber et al. 1999). Another study also suggested limited stability beyond 2 years for the yield of translocations in peripheral lymphocytes after whole-body exposure (Lindholm et al. 1998a), or in the case of partial-body irradiation. Negative result have also been found in subjects 35-40 years after protracted exposure to low doserate external $\gamma$-rays, so that the natural loss of translocation-bearing peripheral lymphocytes cannot fully be compensated so that a temporal decline even of transmissible aberrations takes place (Salassidis et al. 1998).

For dose estimation using chromosome translocations measured by FISH painting, a calibration curve and background translocation frequencies are required. The $\alpha$-coefficient is the slope of a linear dose-response curve or the initial linear portion of a linear-quadratic dose-response curve. It dominates the radiation-induced translocations for acute exposure at <0.4 Gy (Lucas et al. 1995), and for other exposures at low-to-moderate dose-rate. Alpha coefficients for full genome-corrected values of chromosome aberrations in human lymphocytes analysed by FISH painting have been reported as $0.022 \pm 0.010$ translocations per cell $\mathrm{Gy}^{-1}$ (Lucas et al. 1995) or $0.008 \pm 0.008$ (Lindholm et al. 1998b) per cell $\mathrm{Gy}^{-1}$ when irradiated by acute ${ }^{60} \mathrm{Co} \gamma$ rays at room temperature, while $0.009 \pm 0.018$ was reported for cells irradiated at body temperature (Finnon et al. 1999). However, the wide range of standard errors would yield large uncertainties when employed for dose estimation at low-to-moderate doses. Recently, a continuous low dose-rate ${ }^{60} \mathrm{Co}$ irradiation for human lymphocytes at body temperature was conducted and $\alpha=0.024 \pm 0.002$ per cell $\mathrm{Gy}^{-1}$ was derived (Hsieh et al. 1999, Lucas et al. 1999a). With its small standard deviation, this $\alpha$ was employed for the following studies.

Age-specific background chromosome aberrations were reported based on the observation of 1100 metaphases in eight newborns and 47 healthy adults from 19 to 77 years previously (Tucker et al. 1994). A recent study collecting samples from different ethnic groups of 0 to 98 years of age in non-smoking healthy populations suggested a curvilinear relationship between frequencies of chromosome translocations $\left(F_{\mathrm{a}}\right)$ and age as $F_{\mathrm{a}}=7 \times 10^{-4}+6.9 \times 10^{-6}$ age $+1.35 \times 10^{-6}$ age $^{2}$ (Lucas et al. 1999b). Since no significant variation was observed among individuals of the same age or in different ethnic groups, we 
have thus employed these coefficients in this study seeing its appropriateness in Taiwanese populations.

\section{Materials and methods}

\subsection{Subjects and sampling}

A total of 466 subjects was recruited from the exposed cohort population and evaluated for exposure information for TCD dose estimation. These subjects underwent a comprehensive free medical examination by an epidemiology research team in 1997-99. Each individual signed a consent form after detailed explanation. Blood $(30 \mathrm{ml})$ was then collected from each individual during the medical examination. Five male and four female subjects ranging from 10.3 to 48 years old were randomly selected from the eligible pool of applicants; that is, one subject with $\mathrm{TCD}<100 \mathrm{mSv}$, six subjects with TCD between 100 and $1000 \mathrm{mSv}$, and two subjects with TCD $>1000 \mathrm{mSv}$. These individuals were carefully evaluated to rule out a history of cancer, radio/ chemotherapy treatment or cigarette smoking (table 1). The relocation time, defined as the date of moving away from radio-contaminated buildings to the period of blood sampling, ranged from 34 to 82 months. The variation of this physical dose estimation was based on repeated and independent questionnaires of the same individuals for their detailed residency history in the radioactive apartments.

\subsection{Cell cultivation}

For each individual, $1 \mathrm{ml}$ peripheral whole blood was collected and processed within $8 \mathrm{~h}$ of collection by adding to $10 \mathrm{ml}$ RPMI 1640 medium (JRH) supplemented with $20 \%$ foetal bovine serum (FBS; JRH), 1.5\% phytohaemagglutinin-P (PHA-P; Gibco), and $1 \%$ penicillin-streptomycin (Sigma). The cell cultures were maintained in a $5 \% \mathrm{CO}_{2}$ incubator at $37^{\circ} \mathrm{C}$ for $72 \mathrm{~h}$. At the end of cultivation, colcemid $\left(0.04 \mu \mathrm{g} \mathrm{ml}^{-1}\right.$ of final concentration; Gibco) was added to each culture for $4 \mathrm{~h}$ at $37^{\circ} \mathrm{C}$. The cultures were then given a 15-min hypotonic treatment (0.075 M KCl; Sigma), and then fixed in 3:1 methanol:glacial acetic acid. The procedures for preparing metaphase spreads from the cultured cells were modified as described by Lin et al. (1985).

\subsection{Fluorescence in situ hybridization and aberration scoring}

Air-dried and aged slides were coded and chromosome painting was conducted using a commercial kit, with chromosomes 1,2 and 4 as spectrum orange and 3, 5 and 6 as spectrum green (WCP Chromosome

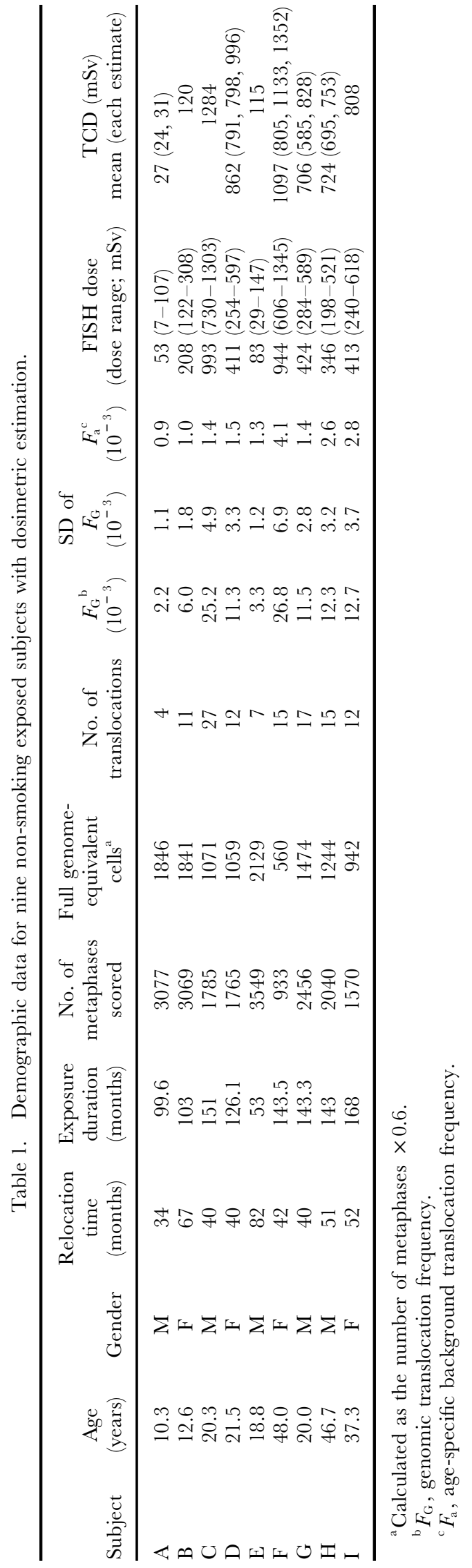


Paint Dual colour DNA FISH Probe, Vysis). The FISH method followed procedures described by Lucas et al. (1995), while chromosome aberrations were analysed using fluorescence microscopy adapted with a triple filter set (FITC/Taxas red/DAPI). Only intact metaphases showing a bright fluorescence signal (green and orange in 1 to 6 WCP) with distinct centromeres under DAPI staining in all six painted chromosome pairs were scored. All aberrations involving the painted chromosomes were recorded and designated $\mathrm{t}(\mathrm{Ab})$ and $\mathrm{t}(\mathrm{Ba})$ by the Protocol for Aberration Identification and Nomenclature Terminology (PAINT) system (Tucker et al. 1995). The painted portions of the two rearranged chromosomes together must contain only one centromere, and similarly for the unpainted. Thus, $t_{\mathrm{c}}=$ $t(\mathrm{Ab})+t(\mathrm{Ba})$. The translocations were scored as incomplete $t_{\mathrm{i}}(\mathrm{Ab})$ if only one unpainted chromosome containing a centromere was attached to a piece of translocated painted acentric material, $t(\mathrm{Ab})$, and was accompanied by another apparently truncated painted monocentric chromosome (B) which 'apparently' failed to rejoin, either because no unpainted piece was attached to the truncated painted chromosome or because the translocated unpainted piece was too small to be detected microscopically. Complete and incomplete translocations were combined as the total translocation events; that is, complete translocations $\left(t_{\mathrm{c}}\right)=t(\mathrm{Ab})+t(\mathrm{Ba})$ and incomplete translocations $\left(t_{i}\right)=t(\mathrm{Ab})+\mathrm{B}$ (Deng et al. 1998, Lucas 1998). The complete and incomplete translocations were each counted as one event. The translocation frequencies were scaled to whole genome frequencies by the following formula for two-colour FISH provided by Lucas (1997): $F_{\mathrm{G}}=F_{\mathrm{p}} /$ $\left\{2.5\left[f_{\mathrm{o}}\left(1-f_{\mathrm{o}}\right)+f_{\mathrm{g}}\left(1-f_{\mathrm{g}}\right)-f_{\mathrm{o}} f_{\mathrm{g}}\right]\right\}$. In brief, the translocation frequency measured by FISH $\left(F_{\mathrm{p}}\right)$ and the genomic translocation frequencies $\left(F_{\mathrm{G}}\right)$ were related as the fraction of the genome covered by the orange probes $\left(f_{0}\right.$, orange fraction as $22 \%$ ), painting chromosomes 1, 2 and 4 , and green probes $\left(f_{\mathrm{g}}\right.$, green fraction as $18 \%$ ) painting chromosomes 3,5 and 6 . This resulted in a detection of $2.05 *[(0.22 * 0.78)+(0.18 * 0.82)-(0.22 * 0.18)]=$ $57.3 \%$ or $\sim 60 \%$ equivalent of all translocations.

\subsection{Biodosimetry estimation by FISH painting}

The dose equivalent dose $(\mathrm{mSv})$ was derived from $D=\left(F_{\mathrm{G}}-F_{\mathrm{a}}\right) / \alpha$, where $F_{\mathrm{a}}$ is the age-specific background translocation based on the equation $F_{\mathrm{a}}=$ $7 \times 10^{-4}+6.9 \times 10^{-6}$ age $+1.35 \times 10^{-6}$ age $^{2}$ (Lucas et al. 1999b) and $\alpha$ is the linear portion of the slope in the linear dose-response curve; that is,
$0.024 \pm 0.002$ translocations per cell $\mathrm{Gy}^{-1}$ for continuous low dose ${ }^{60} \mathrm{Co}$ irradiation at body temperature (Hsieh et al. 1999). The estimated variation in biodosimetry is based on the incorporation of the mean and $1 \mathrm{SD}$ of $\alpha(0.022-0.026)$ and $F_{\mathrm{G}}$.

\section{Results}

Demographic data on the five male and four female subjects are given in table 1 . The age range of those who received an initial excess exposure was from 0 to 36.1 years and the exposure duration was from 4.4 to 14 years. The duration between the blood sampling and relocation from the radioactive environment ranged from 34 to 82 months. The numbers of metaphases scored ranged from 933 in subject $\mathrm{F}$ to 3549 in subject $\mathrm{E}$, or 560-2129 fullgenome equivalents respectively. The numbers of translocations scored ranged from four in subject $\mathrm{A}$ to 27 in subject $\mathrm{C}$, and the frequencies of chromosomal translocations, $F_{\mathrm{G}}$, i.e. the numbers of translocations divided by full-genome equivalent cells, ranged from $2.2 \times 10^{-3} \pm 1.1 \times 10^{-3}$ in subject $\mathrm{A}$ to $26.8 \times 10^{-3} \pm 6.9 \times 10^{-3}$ in subject $\mathrm{F}$. The agespecific background translocation frequencies, $F_{\text {a }}$, ranged from $0.9 \times 10^{-3}$ in subject $\mathrm{A}$ (10.3 years old) to $4.1 \pm 10^{-3}$ in subject $\mathrm{F}$ (48 years old). The biodoses based on FISH-paint detection of chromosomal translocations are shown in table 1 . They ranged from $53 \mathrm{mSv}$ in subject $\mathrm{A}$ to $993 \mathrm{mSv}$ in subject $\mathrm{C}$. The physical doses of TCD (table 1) ranged from 27 $\mathrm{mSv}$ in subject A to $1284 \mathrm{mSv}$ in subject $\mathrm{C}$.

The relationship between biodose $\left(D_{\text {fish }}\right)$ and TCD $\left(D_{\mathrm{TCD}}\right)$ estimates is plotted in figure 1 . The data were fitted by a linear model: $D_{\mathrm{fish}}=a+b D_{\mathrm{TCD}}$ and by a linear-quadratic model of the form: $D_{\mathrm{fish}}=a+b$ $D_{\mathrm{TCD}}+c D_{\mathrm{TCD}}^{2}$. Fitting the data with a linear-quadratic model produced an equation of the form: $D_{\mathrm{fish}}=$ $110.3-0.1 D_{\mathrm{TCD}}+0.00065 D_{\mathrm{TCD}}^{2}\left(r^{2}=0.934\right)$, where $D$ is dose $(\mathrm{mSv})$, or fitting with a linear model produced an equation of the form: $D_{\mathrm{fish}}=$ $-4.1+0.68 D_{\mathrm{TCD}}\left(r^{2}=0.84\right)$. To examine the correlation between biodose and TCD in the same individuals, we refitted these data after subtracting background (figure 1). The TCD error bars were calculated as $1 \mathrm{SD}$ from the mean in cases where multiple sampling occurred. The curves went through zero and were of the form: $D_{\mathrm{fish}}=0.53$ $D_{\mathrm{TCD}}+1.26 \times 10^{-4} D_{\mathrm{TCD}}^{2}$ or $D_{\mathrm{fish}}=0.65 D_{\mathrm{TCD}}$. The biodose ranges were calculated from the SD of $\alpha$ and $F_{\mathrm{G}}$. For example, the biodose for the 48-year-old subject $\mathrm{F}$ was calculated with a background translocation frequency, $F_{a}$, of $4.1 \times 10^{-3}$ and the measured translocation frequency, $F_{\mathrm{G}}, 26.8 \pm 6.9$ per 1000 cells. Applying the measured $\alpha=0.024 \pm 0.002$ (Hsieh et al. 


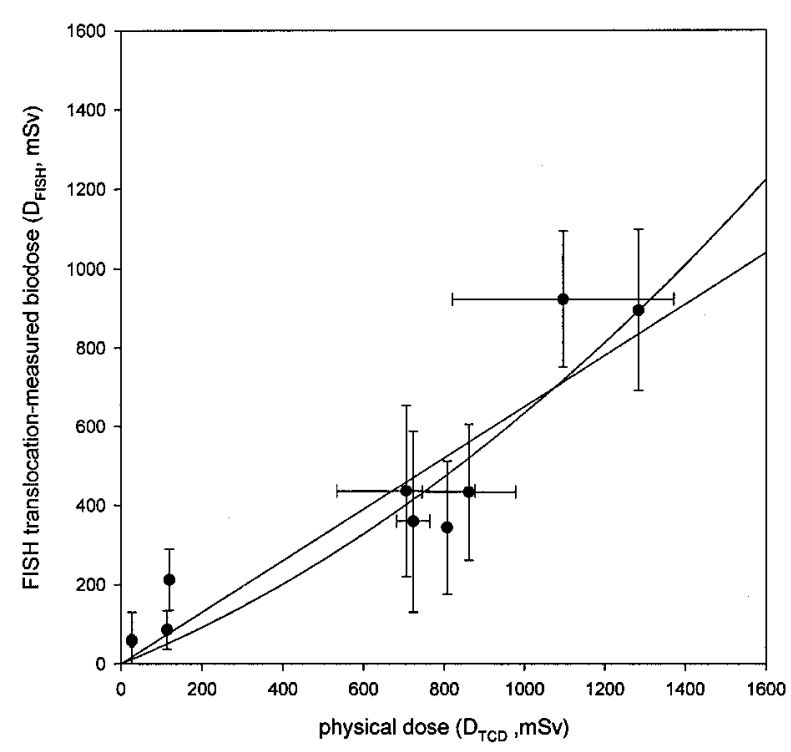

Figure 1. Comparison between the physical dose, $D_{\mathrm{TCD}}$, and translocation-measured biodose, $D_{\mathrm{fish}}$. The linear and linear-quadratic lines fit the data equally well and after subtraction of background doses they both go through the origin.

1999), $D_{\text {fish }}$ was calculated to be $944 \mathrm{mSv}$ with $F_{\mathrm{G}}=26.8 \times 10^{-3}$. $D_{\text {fish }}$ ranged from 606 to 1345 $\mathrm{mSv}$, calculated using $F_{\mathrm{G}}=19.9-33.7$ with $\alpha=$ $0.022-0.026$.

The dose range estimation of $D_{\mathrm{TCD}}$ was based on separate questionnaires conducted repeatedly as the living histories of the same subjects, except subjects B, C, E and I. For example, subjects F had three repeated living history questionnaires and $D_{\mathrm{TCD}}$ ranged from 805 to $1352 \mathrm{mSv}$. Mostly, the biodoses based on chromosome translocations measured using FISH painting were lower than those of the TCD. The large SD of TCD are due primarily to error in results of questionnaires to determine the location of the exposed individuals during the irradiation period.

\section{Discussion}

It is rare to find such a large population of families exposed in their homes over such a protracted period. This study presents both unique dose reconstruction difficulties and opportunities in human biodosimetry. Reconstructing the physical doses posed challenges because the exposure position of individuals had to be ascertained by questionnaires. The position of people and objects in the apartment varied over time, presenting challenges to efforts in physical dose reconstruction. This unique study gave an opportunity to use biodoses, measured by FISH, as a check on the estimated physical dose. Thus, by comparing doses determined for a small subgroup of exposed individuals we were able to evaluate the accuracy of the physical doses reconstructed; assuming that FISH can be used as a standard for whole-body fully penetrating exposures.

\subsection{Measured biodose compared with calculated physical dose}

The results show differences between the measured biodoses and the calculated physical doses, as also reported in another recent study that applied whole chromosome 2, 4 and 12 painting for biodose estimation on 56 exposed and 36 reference subjects and adapting the generic $\alpha$ of 0.02 from an acute irradiation in vitro study of (Finnon et al. 1999, Chen et al. 2000).

As can be seen from table 1 and figure 1, the physical doses are about $35 \%$ higher than the biodoses. The slope of the linear regression between the physical doses and FISH-measured biodoses for the nine exposed individuals is 0.65 and the correlation coefficient is 0.89 . Nevertheless, there is a strong correlation between these two doses, and there are plausible reasons that may account for the differences. These include: (1) the furniture inside the room may have provided shielding for the exposed individuals. This would tend to cause an over estimation of the physical dose. (2) The exposed subjects at different angles to the radioactive sources would receive less exposure than those derived from projected physical doses of exposure by the TCD, which may not take the angle of the source to the victim into account. (3) Origins of discrepancy in biodose estimates might be caused by circulating lymphocytes carrying lethal chromosome aberrations, which may limit their life span. At high doses, some translocations may not be completely stable over time. Data from Matsumoto et al. (1998) appear to suggest that translocations persist after 5 days following acute $4 \mathrm{~Gy}{ }^{137}$ Cs irradiation, but showed a significant reduction from 2 to 5 days. Cell death resulting from accompanying unstable aberrations may explain the decline in translocation frequencies. However, at the lower doses this should not be a problem because translocations should be stable over time (Lucas 1999). Whereas this is not a crucial discrepancy, there are possible reasons that may account for the difference between the doses. An argument can be mounted that the reconstructed physical doses may be expected to be slightly higher than the measured biodoses, because of the questionnaire and geometrybased physical dose reconstruction methods as well as perhaps some loss in translocations for the higher exposures.

Subjects A and B were the only exceptions for the 
biodose being higher than the physical dose in this study. However, both $\mathrm{A}$ and $\mathrm{B}$ had been irradiated in utero for about 4 and $14 \mathrm{mSv}$, which accounted for 13.0 and $11.8 \%$ of the TCD total excessive exposure, respectively. These results are consistent with reported data showing a high sensitivity for intrauterine exposure. An increased radiosensitivity in human cord blood cells revealed that 150 cGy X-rays induced a significant increase in the frequencies of dicentric chromosome aberrations in the blood of newborns than in those of the adults (Lloyd and Reeder 1979). Additionally, the survival in $\mathrm{G}_{0}$ phase peripheral blood lymphocytes to ${ }^{60}$ Co $\gamma$-irradiation in 18 cord blood samples were shown to have a significant increase in radiosensitivity compared with 21 reference subjects (Waugh et al. 1991).

\subsection{Variation in dose estimation}

It is possible that individuals whose exposure was in the higher dose range may have received subacute radiation. If so, this would suggest a $\beta$ (quadratic) contribution to the total dose for these particular individuals. We calculated doses with and without a $\beta$ contribution for the two subjects who received a higher dose, subjects $\mathrm{C}$ and F. They had TCD close to $1 \mathrm{~Sv}$ with an estimated biodoses of 993 and $944 \mathrm{mSv}$, calculated using an $\alpha$-coefficient of $0.024 \pm 0.002$. Applying a linear-quadratic model with $\alpha=0.024 \pm 0.005$ and $\beta=0.0023 \pm 0.008$ (Hsieh et al. 1999), the modified biodoses were 912.4 and $871.2 \mathrm{mSv}$ for the respective $\mathrm{C}$ and $\mathrm{F}$ subjects. These doses are not significantly different using the two models. The linear-quadratic model gave $\mathrm{r}^{2}=0.925$, similar to the 0.934 for the linear model. Hence, the simple linear model was reliable for biodose calculation using our data, and these higher exposures appear to have been chronic.

The TCD dose estimates showed large variation when assayed in the same individuals on different occasions after they relocated from radioactive contaminated apartments. For example, subject $\mathrm{F}$ was assayed three times independently and the living history questionnaires were collected, while the same geometric layout was employed for TCD dose estimation. TCD for subject F ranged from 804.4 to 1351.6 $\mathrm{mSv}$. The variation from daily outdoor duration could introduce large variation in TCD estimation, especially in relatively high dose-rate radioactive apartments. On the other hand, subjects D and G are siblings with a small age difference. They reported regular daily study schedule at school and very similar daily occupancy duration at home. TCD for them were shown with smaller variation, as the occupancy information was in agreement with each other. In general, recall biases may be incurred during living history questionnaires. However, systematic validation of these questionnaires and rationalization of the uncertainty is difficult in most of these individuals with historical exposure.

A higher physical dose estimate compared with FISH biodose measurements has been reported before. Moore et al. (1997) measured a biodose of 9 cGy by FISH painting of chromosome translocations, which was significantly lower than $25 \mathrm{cGy}$ derived physical dose estimations of 126 liquidators from the Chernobyl nuclear reactor accident in 1986. Some of them possessed official Chernobyl dosimetry cards based on TLD, while a majority was interviewed and the dose was estimated on the type and location of the work being performed. The physical doses of these liquidators were uncertain and poorly correlated with biological doses. Another 118 liquidators were estimated by chromosomal painting using stable chromosome aberrations and no correlation was found with those from the estimated physical doses (Littlefield et al. 1998). It thus appears that uncertainties existing in indirect physical dose estimation questionnaires are critical to dose reconstruction.

\section{Conclusions}

Good agreement between the biodose and physical dose was observed. These results support the use of stable chromosome translocation frequencies, measured using FISH painting, for dose reconstruction in extremely protracted low dose-rate $\gamma$-radiation exposure in human populations. The biodosimeters in this study provide a strong correlation and validation for the TCD dose assessment, which can be applicable for further epidemiological studies.

\section{Acknowledgements}

The authors are grateful to Dr Jung-Der Wang and Shyh-Dye Lee of the National Taiwan University, Dr Jing-shiang Hwang of the Sinica Academia, and Dr Motion Tsai of National Yang Ming University for contributory discussions during the preparation of the manuscript. The National Health Research Institute (NHRI) supported the work from 1995 to 2000, and W.A.H. was supported by a doctoral fellowship from the NHRI.

\section{References}

Cardarelli, J. N., Elliott, L., Hornung, R. and Chang, W. P., 1997, Proposed model for estimating dose to inhabitants of ${ }^{60} \mathrm{Co}$ contaminated buildings. Health Physics, 72, 351-360. 
Chang, W. P., 1993, Spread of Taiwan's radiation panic. The Lancet, 342, 1544.

Chang, W. P., Chan, C. C. and Wang, J. D., 1997a, ${ }^{60}$ Co contamination in recycled steel resulting in elevated civilian radiation doses: causes and challenges [see comments]. Health Physics, 73, 465-472.

Chang, W. P., Hwang, B. F., Wang, D. and Wang, J. D., 1997b, Cytogenetic effect of chronic low dose, low doserate gamma-radiation in residents of irradiated buildings. Lancet, 350, 330-333.

Chang, W. P. and KAU, J., 1993, Taiwan: exposure to high doses of radiation. Lancet, 341, 750.

Chang, W. P., Lin, Y. P., Hwang, P. T., Tang, J. L., Chen, J. D. and LEE, S. D., 1999a, Persistent leukocyte abnormalities in children years after previous long-term low dose rates radiation exposure. British fournal of Haematology, 106, 954-959.

Chang, W. P., H wang, J. S., H ung, M. C., H u, T. H., Lee, S. D. and Hwang, B. F., 1999b. Chronic low dose $\gamma$-radiation exposure alters distribution of lymphocyte subpopulations in residents of radioactive buildings in Taiwan. International Journal of Radiation Biology, 75, 1231-1239.

Chen, F. D., Chen, K. Y., Ngo, F. Q. H., Lin, C. H., T sai, S. T., Ling, T. S., Whang-Peng, J. J. K., EdWARdS, A. A., Lloyd, D. C. and Chen, W. L., 2000, Chromosomal damage in long-term residents of houses contaminated with cobalt-60. Lancet, 335, 726.

Chen, W. L., Hwang, J. S., Hu, T. H., Chen, M. S. and Chang, W. P., 2001, Lenticular opacities in populations exposed to chronic low dose-rate gamma-radiation from radiocontaminated buildings in Taiwan. Radiation Research (in press).

Deng, W., Morrison, D. P., Gale, K. L. and Lucas, J. N., 1998, Biological dosimetry of beta-ray exposure from tritium using chromosome translocations in human lymphocytes analysed by fluorescence in situ hybridization. Radiation Research, 150, 400-405.

Finnon, P., Moquet, J. E., Edwards, A. A. and Lloyd, D. C., 1999, The ${ }^{60}$ Co gamma ray dose-response for chromosomal aberrations in human lymphocytes analysed by FISH; applicability to biological dosimetry. International Fournal of Radiation Biology, 75, 1215-1222.

Hsieh, W. A., Deng, W., Chang, W. P., Galvan, N., OWens, C. L., Morrison, D. P., Gale, K. L. and LuCAS, J. N., 1999, Alpha coefficient of dose-response for chromosome translocations measured by FISH in human lymphocytes exposed to chronic ${ }^{60}$ Co gamma rays at body temperature. International Fournal of Radiation Biology, 75, 435-439.

H uber R., Braselmann, H., Kulka, U., SchumacherGeorgiadou, V., Bayerl, A., Molls, M. and BAUCHINGER, M., 1999, Follow-up analysis of translocation and dicentric frequencies, measured by FISH-chromosome painting in breast cancer patients after partialbody radiotherapy with little bone marrow exposure. Mutation Research, 446, 103-109.

HWang, J. S., Chan, C. C., Wang, J. D. and Chang, W. P., 1998, Radiation exposure modeling for apartment living spaces with multiple radioactive sources. Health Physics, 74, 379-386.

Lin, C. C., Droper, P. N. and Debraekeleer, M., 1985, High resolution chromosomal localization of the $\mathrm{B}$ gene of the human $\beta$-globin gene complex by in situ hybridization. Cytogenetics and cell Genetics, 39, 369-374.

Lindholm, C., TekKel, M., Veidebaum, T., Ilus, T. and
SAlOMAA, S., 1998a, Persistence of translocations after accidental exposure to ionizing radiation. International Fournal Radiation Biology, 74, 565-571.

Lindholm, C., LuomahaARa, S., Koivistoinen, A., Ilus, T., Edwards, A. A. and SalomaA, S., 1998b, Comparison of dose-response curves for chromosomal aberrations established by chromosome painting and conventional analysis. International Fournal of Radiation Biology, 74, 27-34.

LitTlefield, L. G., McFee, A. F., SAlomaA, S. I., T UCKER, J. D., InSKIP, P. D., SAYER, A. M., LINDHOLM, C., MÄKINEN, S., Mustonen, R., Sorensen, K., TeKkel, M., Veidebaum, T., Auvinen, A. and Boice, J. D., 1998, Do recorded dose overestimate true doses received by Chernobyl cleanup workers? Results of cytogenetic analysis of Estonian workers by fluorescence in situ hybridization. Radiation Research, 150, 237-249.

Lloyd, D. C. and ReEDER, E. J., 1979, Chromosome aberrations in in vitro irradiated lymphocytes from human cord blood. Experientia, 35, 176-177.

LuCAS, J. N., 1997, Dose reconstruction for individuals exposed to ionizing radiation using chromosome painting. Radiation Research, 148(S), S33-38.

LuCAs, J. N., 1998, Cytogenetic signature for ionizing radiation. International fournal of Radiation Biology, 73, 15-20.

LuCAS, J. N., 1999, Letter to the Editor: Translocation frequencies for low to moderate doses remain constant over time. International fournal of Radiation Biology, 75, 655-656.

Lucas, J. N., Awa, A., Straume, T., Poggensee, M., Kodama, Y., Nakano, M., O htaki, K., Weier, H. U., PINKEL, D., GRAY, J. et al., 1992, Rapid translocation frequency analysis in humans decades after exposure to ionizing radiation. International Fournal of Radiation Biology, 62, 53-63.

Lucas, J. N., Deng, W., Hsieh, W. A., Galvan, N., Gale, K. L. and Morrison, D. P., 1999a, Exposure temperature, but not donor age, is a confounding factor for in vitro translocation production by chronic irradiation. International fournal of Radiation Biology, 75, 673-680.

Lucas, J. N., Deng, W., Moore, D., Hill, F., Wade, M., Lewis, A., Sailes, F., Kramer, C., Hsieh, A. and GALVAN, N., 1999b, Background ionizing radiation plays a minor role in the production of chromosome translocations in a control population. International fournal of Radiation Biology, 75, 819-827.

Lucas, J. N., Hill, F., Burk, C., Fester, T. and Straume, T., 1995, Dose-response curve for chromosome translocations measured in human lymphocytes exposed to ${ }^{60} \mathrm{Co}$ gamma rays. Health Physics, 68, 761-765.

Lucas, J. N., Hill, F. S., Burk, C. E., Cox, A. B. and STRAUME, T., 1996, Stability of the translocation frequency following whole-body irradiation measured in rhesus monkeys. International Fournal of Radiation Biology, 70, 309-318.

Matsumoto, K., Ramsey, M. J., Nelson, D. O. and T UCKER, J. D., 1998, Persistence of radiation-induced translocations in human peripheral blood determined by chromosome painting. Radiation Research, 149, 602-613.

Moore, D. H., T UCKer, J. D., Jones, I. M., LANGlois, R. G., Pleshanov, P., Vorobtsova, I. and Jensen, R., 1997, A study of the effects of exposure on cleanup workers at the Chernobyl nuclear reactor accident using multiple end points. Radiation Research, 148, 463-475.

Salassidis, K., BraselmanN, H., O Kladnikova, N. D., Pressl, S., Stephan, G., Snigiryova, G. and BAUChINGER, M., 1998, Analysis of symmetrical translocations for retrospective biodosimetry in radiation workers 
of the Mayak nuclear-industrial complex (Southern Urals) using FISH-chromosome painting. International Fournal of Radiation Biology, 74, 431-439.

Salassidis, K., Salassidis, K., Georgiadou-Schumacher, V., BraselmanN, H., Muller, P. and Peter, R. U., 1995, Chromosome painting in highly irradiated Chernobyl victims: a follow-up study to evaluate the stability of symmetrical translocations and the influence of clonal aberrations for retrospective dose estimation. International Journal of Radiation Biology, 68, 257-262.

Straume, T. and Bender, M. A., 1997, Issues in cytogenetic biological dosimetry: emphasis on radiation environments in space. Radiation Research, 148, S60-S70.

Straume, T., Lucas, J. N., Tucker, J. D., Bigbee, W. L. and LANGLOIS, R. G., 1992, Biodosimetry for a radiation worker using multiple assays. Health Physics, 62, 122-130.

T UCKer, J. D., LeE, D. A., R AMSeY, M. J., Briner, J., O LSEN, L. and Moore, D. H. II, 1994, On the frequency of chromosome exchanges in a control population measured by chromosome painting. Mutation Research, 313, 193-202.

T ucker, J. D., Morgan, W. F., Awa, A. A., Bauchinger, M., Blakey, D., Cornforth, M. N., Littlefield, L. G., Natarajan, A. T. and Shasserre, C., 1995, PAINT: a proposed nomenclature for structural aberrations detected by whole chromosome painting. Mutation Research, 347, 21-24.

T ucker, J. D., Lee, D. A., Ramsey, M. J., Briner, J., Olsen, L. and Morre II, D. H., 1994, On the frequency of chromosome exchanges in a control population measured by chromosome painting. Mutation Research, 313, 193-202.

Wang, J. C., Lin, Y. P., HWANG, J. S. and Chang, W. P., 2001, Physical heights of children with chronic low dose gammaradiation exposure in radiocontaminated buildings. International Fournal of Radiation Biology, 77, 117-125.

WAng, T. Y., Chen, C. J., Guo, G. L., Wu, S. F., HWAng, B. F., Chen, D. J. Y., Lee, Y. M. and Chang, W. P., 1999, Prevalence of lens opacity in population with chronic low dose gamma-radiation exposure from radioactive apartments in Taiwan. In Ocular Radiation Risk Assessment. NATO series publications in NATO Advanced Research Workshop (Dordrecht: Kluwer), pp. 191-196.

Waugh, A. P. W., Beare, D. M., Arlett, C. F., Green, M. H. L. and Cole, J., 1991, Comparative human cellular radiosensitivity: IV. The increased sensitivity of human neonatal cord blood lymphocytes to r-irradiation compared with lymphocytes from children and adults. International Fournal Radiation Biology, 59, 767-776. 